\title{
Psikoterapi Süpervizyonunda Paralel Süreç: Bir Vaka Çalışması
}

\author{
Ali Can Gök \\ Orta Doğu Teknik Üniversitesi
}

\begin{abstract}
Özet
Paralel süreç kavramı, psikoterapi süpervizyonu sürecinde, hem terapi hem de süpervizyon ikililerindeki ilişkisel örüntülerin bilinçdışı bir şekilde tekrarlanmasına denmektedir. Birçok terapist ve süpervizör paralel süreci süpervizyonda önemli bir araç ve değerli bir iletişim biçimi olarak görmektedir. Paralel süreç kavramı alanda dikkat çeken bir konu olmasına rağmen, görgül bir şekilde yeterli olarak desteklenmemiştir. Bu makale paralel süreç kavramı üzerine bir literatür derlemesi ve örnek olarak bir vaka sunumu içermektedir.
\end{abstract}

Anahtar kelimeler: Paralel Süreç, Psikoterapi, Süpervizyon, Süpervizyon İkilisi, Terapötik İkili 


\section{Psikoterapi Süpervizyonunda Paralel Süreç: Bir Vaka Çalışması}

Paralel süreç psikoterapi süpervizyonu literatüründe oldukça bilinen ve çalışılan bir kavramdır (Morissey ve Tribe, 2001; Raichelson, Herron, Primevera, Ramirez, 1997; Grey ve Fiscalini, 1987), ve özellikle psikoanalitik ekolde önemi vurgulanmıştır (Raichelson, ve diğerleri, 1997; Grey ve Fiscalini, 1987). Psikoterapi süpervizyonu, terapistin bir veya daha fazla danışanla yaptığı çalışmaların ele alındığı ve doğası gereği üç kişiyi içeren bir süreçtir (Tracey, Bludworth, Glidden-Tracey, 2012). Süpervizyon, en önemlisi danışana daha iyi bir yardım sunma olmak üzere, birçok işleve sahiptir (Morissey ve Tribe, 2001). Bu üç kişilik ilişki içerisinde terapötik ikili ve süpervizyon ikilisi bulunmaktadır. Paralel süreç, terapötik ikili (terapist ve danışanı içermekte olan) ve süpervizyon ikilisinde (süpervizör ve terapisti içermekte olan) ilişkisel örüntülerin bilinçdışı bir şekilde tekrar edilmesi ile ortaya çıkmaktadır (McNeill ve Worthen, 1989). Paralel süreci tanımlamak için kriterler biraz belirsiz kalmaktadır (Grey ve Fiscalini, 1987; Watkins, 2012). Bu sebeple Grey ve Fiscalini (1987) paralel süreci betimleyecek kriterleri:

a. Birbiriyle ilişkili olan iki ya da daha fazla durumun olması

b. Bu durumlarda aynı savunma mekanizmalarının kullanılması

c. Bu ilişkili durumların ortak bir elemanının olması ve o elemanın kullanılan savunma mekanizmasını durumlar arasında taşıyan kişi olması

d. Ve durumlar arasında savunma mekanizmasını taşıyan kişinin ikinci durumda ilkinde olduğunun karşı durumunda olması

şeklinde özetlemiştir. Bu kriterlere göre, örneklemek gerekirse: I. durum ve II. durumumuz olsun ve bu iki durum birbiriyle ilişkili olsun. Her durumda da A ve B rolleri olsun. X kişisi bu her iki durumda da yer alırken I. durumda A rolünde olup, II. durumda da B rolünde olması oluşan süreci paralel süreç olarak adlandırabilmemizi sağlayacaktır.

Paralel sürecin, "gerekli ve kaçınılmayacak bir süreç" olduğunu söyleyenler bulunmakla beraber (McNeill ve Worthen, 1989; Searles, 1955; Tracey ve diğerleri, 2012), "tamamiyla bir yanılsama olduğunu" savunan terapist ve süpervizörler de vardır (Lesser, 1983). Birçok terapist ve süpervizör paralel süreci süpervizyonda önemli bir araç ve değerli bir iletişim biçimi olarak algilamaktadır (McNeill ve Worthen, 1989; Morissey ve Tribe, 2001). Paralel süreci ele almay1 hedefleyen müdahaleler süpervizyon sürecinin kalitesini arttırmaktadır (Morissey ve Tribe, 2001). Mamafih, paralel sürecin her süpervizyonda mı olduğu yoksa sadece belirli ilişkilerde mi ortaya çıktığı konusunda soru işaretleri vardır (Tracey ve diğerleri, 2012; Watkins, 2012). Bir çalışmanın sonuçları paralel sürecin her süpervizyonda var olduğunu ortaya koymaktadır, fakat bu konuda emin olarak bir şey söylenmesi için bu ve benzeri çalışmaların tekrarlanması gerekmektedir (Raichelson ve diğerleri, 1997).

Paralel süreç kavramı alanda dikkat çeken bir konu olmasına rağmen, görgül olarak yeterli şekilde desteklenmemiştir (Grey ve Fiscalini, 1987; Raichelson ve diğerleri, 1997; Tracey ve diğerleri, 2012). Kavramın kendisi can alıcı olmasına rağmen (Mothersole, 1999) bazı yazarlar "tekinsiz" olarak görmektedirler (Grey ve Fiscalini, 1987; Mothersole, 1999). Bir araştırma, paralel sürecin varlığının hem terapistler hem de süpervizörler tarafından süpervizyonun bir parçası olarak tanındığını ve kuramsal yönelimin paralel sürecin varlığını kabul etme konusunda bir fark yaratmadığını rapor etmiştir (Raichelson ve diğerleri, 1997). Öte yandan, paralel süreç 
üzerine düşünmek psikolojik bağımsızlık ve kişilerarası etki üzerine temel felsefi sorunları da gündeme taşımaktadır (Grey ve Fiscalini, 1987). Kimi araştırmacılar paralel sürecin yarattığı etkinin bu tartışmalara konu olacak kadar büyük olmadığını sadece süpervizyon ve terapinin gidişatını etkileyebilecek ufak eğilimler oluşturduğunu dile getirmektedir (Tracey ve diğerleri, 2012).

Paralel sürecin kökenleri psikoanalizin aktarım ve karşıaktarım kavramlarına dayanmaktadır (Sumeral, 1994; McNeill ve Worthen, 1989; Morissey ve Tribe, 2001). Terapötik ikilideki terapistin karşıaktarımı ile süpervizyon ikilisinde süpervizörün karşıaktarımının benzeşmesi ile farkına varılmaya başlanılmıştır (McNeill ve Worthen, 1989). Fakat bazı yazarlar, aşağıda da değinileceği üzere, paralel süreci karşıaktarım kavramı çerçevesi içerisinde ele almaktan kaçınmıştır (Searles, 1955). Bunun yanı sıra, paralel sürecin varlığı, bilinçdışı öğeleri dahil etmeden, psikoanalitik ekol dışındaki terapi ekolleri tarafından da desteklenmiştir (Raichelson ve diğerleri, 1997; Tracey ve diğerleri, 2012). Paralel süreç kavramı psikanalitik yönelim kaynaklı olmasına rağmen diğer yönelimlerden de kabul görüp çalışılmıştır (Tracey ve diğerleri, 2012).

\section{Paralel Sürecin Nedenleri}

Bu başlık altında paralel sürece katkıda bulunan bazı faktörler incelenecektir. Paralel sürecin nedenleri üzerine bir fikir birliği sağlanmamış (Morissey ve Tribe, 2001) olsa da kısmi açıklamalar bulunmaktadır (Mothersole, 1999). Öncelikle, terapi ile süpervizyon arasındaki durumsal benzerliklerin paralel sürece katkısı olan nedenlerden biri olabileceği öne sürülmüştür (Sach ve Shapiro, 1976). Çeşitli kaynaklar bu durumsal benzerlikleri otorite ve yakınlık kavramları ile açıklamışlardır (Grey ve Fiscalini, 1987; Tracey ve diğerleri, 2012; Doehrman, 1976). Bunun yanı sıra, süpervizyon ve terapi arasındaki bir başka benzerlik de ikisinde de "yardım alma" ve "yardım etme" davranışlarının bulunması ve terapi ilişkisinde yardım etme rolünde olan terapistin süpervizyon ilişkisinde yardım alma pozisyonuna geçiyor olmasıdır (McNeill, ve Worthen, 1989). Yardım alma ve yardım etme davranışları sırasında kurulan otorite ve yakınlık dereceleri süpervizyon ve terapi durumları arasında benzeşebilmektedir (Tracey ve diğerleri, 2012). Eğitimine devam eden terapistin, didaktik bir şekilde öğretilen -kişiliğinden bağımsız- becerileri öğrenmekle kalmadığı, bunun yanı sıra kendi kişiliği ile çok yakın ilişkide bulunan profesyonel bir kimlik oluşturduğu savunulmuştur (Doehrman, 1976). Bu durumun süpervizyonu didaktik bir eğitimden ziyade -terapi olmasa da- terapi benzeri bir durum haline getirdiği, dolayısıyla terapi ile süpervizyon arasında benzer gündemlerin oluşmasına neden olduğu düşünülmüştür (Doehrman, 1976). Yukarıdakilere ek olarak, Ekstein ve Wallerstein (1958) paralel sürecin bir öğrenme biçimi olduğunu savunmuş; terapistin, terapi sürecinde karşılaştığı ve ele alamadığı materyali süpervizyonda tekrar edip süpervizörün benzer meseleleri ele alış tarzını öğrendiğini ifade etmişlerdir. Sach ve Shapiro (1976), paralel sürecin sözel olarak ifade edilemeyenlerin aktarılması için kullanılan bir iletişim aracı olduğunu söylemiş; ele alınamayan materyalin terapiden süpervizyona -sözel olarak ifade edilemediğinden- bu iletişim kanalıyla aktarıldığı düşünmüşlerdir (Ekstein ve Wallerstein, 1958).

\section{Paralel Süreç Kavramının Tarihsel Gelişimi}

Bu makalede 'paralel süreç' olarak adlandırılan olguya, geçmişte literatürde 'yansıma süreci', 'aynalama' ve 'paralel harekete geçme' gibi isimler de verilmiştir (Morissey ve Tribe, 2001). Paralel süreç kavramına ilk olarak Searles (1955) 'yansıma süreci’ olarak değinmiştir. Üç 
sene sonra, Ekstein ve Wallerstein (1958) aynı olguyu paralel süreç olarak adlandırmıştır. Searles (1955) süpervizyon sürecinde süpervizörün yaşadığı duyguların terapist ve danışanı arasındaki ilişki ile alakalı zengin bir bilgi kaynağı olduğu fikrini savunmuştur. Bununla birlikte süpervizörün duygusal deneyiminin yapısının genellikle terapi ilişkisinde yaşanan zorluğu yansıttı̆̆ını öne sürmüş; süpervizörün, bilinçdışı bir şekilde taşınan duygusal bilgileri ele almadığı sürece, danışan hakkındaki bilgisinin terapistin sözel olarak anlattıklarıyla sınırlı kaldığını öne sürmüştür (Searles, 1955). Bir yandan da, o zamanın paradigması içerisinde süpervizörün duygusal deneyimlerinin ele alınması kolay kabul edilebilecek bir durum olarak görülmemiştir (Meerloo, 1952). Süpervizörün olumsuz duygulanımı bir karşı aktarım sorunu olarak görülmüş ve süpervizyon sürecinde istenmeyen bir durum olarak ele alınmıştır. Yansıtma süreci, karşı aktarım kavramından ayrı bir olgu olmasıyla birlikte karşı aktarım ile ilişkili de bir olgudur. Searles’a göre (1955) karşı aktarımda duygusal deneyimin kaynağı olarak süpervizörün kendi geçmiş deneyimleri olarak görülmekteyken yansıtma sürecinde ise bu duygusal deneyimin kaynağı danışandır ve terapist aracılığıyla süpervizöre taşınmıştır. Searles'ın (1955) en büyük katkılarından birisi de süpervizörün duygusal deneyimlerinin zararlı olarak görülmeyip, faydalı bir araç olarak ele alınmasıdır (Mothersole, 1999). Öncesinde süpervizörün duygusal deneyimleri süpervizyon sürecini sekteye uğratacak bir konu olarak görülmüştür (Mothersole, 1999).

\section{Paralel Sürecin Yönü}

Paralel süreç en başta, başlangıç noktası danışanın bilinçaltı olduğu tek yönlü bir süreç olarak görülmüştür (Grey ve Fiscalini, 1987; Searles, 1955). Fakat, bazı yazarlar başlama noktasının danışan olduğu kadar süpervizörün de olabileceği iki yönlü bir süreç olarak ele almışlardır (Doehrman, 1976; Tracey ve diğerleri, 2012). Başlangıç noktasının süpervizör olduğu paralel süreç durumlarında, terapist danışanına süpervizyonda süpervizörünün kendisine davranma biçimini andırır şekilde davranmaktadır (Doehrman, 1976; Tracey ve diğerleri, 2012). Mothersole (1998), üç tip paralel süreç tanımlamıştır. Birinci tip paralel süreç, Searles'in (1955) tanımladığı gibi, başlangıç noktasının danışan olduğu, terapötik ilişkideki örüntünün süpervizyon ilişkisine aktarıldığg durum olarak betimlenmiştir. İkinci tip paralel süreçte ise süpervizyon ilişkisindeki sorunlar terapistten kaynaklı olarak hem süpervizyon ilişkisine hem de terapi ilişkisine yansımaktadır. Bu durumun gerçek bir paralel süreçten ziyade terapistin çözülmemiş duygusal bir çatışmasını yahut beceri eksikliğini gösterdiği düşünülmektedir (Mothersole, 1998). Son olarak da üçüncü tip paralel süreç, Doehrman'ın da (1976) vurguladığı gibi, süpervizörün terapiste olumsuz bir örnek teşkil ettiği durum olarak tanımlanmıştır.

Bunların yanı sıra, süpervizyon ve terapinin karmaşık yapısı göz önünde bulundurulduğunda, paralel süreç başlangıç noktası olan bir süreçten ziyade döngüsel bir dinamik olarak da görülmektedir (Morissey ve Tribe, 2001). Bazı yazarlar, paralel sürecin süpervizör, terapist ve danışan üçlüsünün birbirinin içine geçen süreçlerinin ortaya çıkardığ 1 oynanan bir “oyun” olduğu görüşünü savunmuştur (Grey ve Fiscalini, 1987). Bu görüşte de paralel süreç bilinçdışı duygusal çatışmalardan çıkmaktadır. Terapist danışanın savunma mekanizmasını süpervizyon sürecine bilinçdışı bir şekilde taşımaktadır ve buradaki amaç danışanla ilişkili problemin ne olduğu mesajını vermektir. Süpervizör de o davranış örüntüsünü terapistin danışana davrandığ 1 bir şekilde davranış örüntüsünü tamamlamaktadır (Grey ve Fiscalini, 1987). Bu davranışlar, süpervizör ile terapistin karakteristik davranışları olarak görülmemekle beraber danışanın davranış örüntülerini andırmaktadır (Grey ve Fiscalini, 1987). 


\section{Görgül Araştırmalar}

Önceden de belirtildiği gibi paralel sürecin karmaşık doğası gereği ve bu karmaşık olguyu ölçmenin teknik zorluklarından ötürü paralel süreci araştıran görgül araştırma sayısı çok azdır (Tracey ve diğerleri, 2012). Paralel süreç üzerine alanyazının çoğu vaka çalışmalarına dayanmaktadır. Dolayısıyla, bu durum genelleyebilme sorunlarını ortaya koymaktadır (Mothersole, 1999; Tracey ve diğerleri, 2012). Paralel süreci inceleyen ilk çalışma Doehrman'ın (1976) çı̆̆ır açan çalışmasıdır. Doehrman (1976) paralel sürecin her zaman danışanın bilinçdış1 nevrotik ihtiyaçlarından kaynaklanmayabileceğini ortaya koyan ilk kişidir. Terapötik ikilinin ilişki örüntüsünün süpervizyon ikilisine sirayet edebileceği gibi süpervizyon ikilisinin de örüntülerinin terapötik ikiliye geçebileceğini söyleyerek paralel sürecin iki yönlü olabileceğini iddia etmiştir (Doehrman, 1976). Çalışmanın bir başka önemli bulgusu da paralel sürecin süpervizyonun her gelişim sürecinde ortaya çıkabileceğini göstermiş olmasıdır. Dahası, süpervizyon sürecinde daha ileri olan terapistlerin yeni başlayanlara göre paralel sürecin yorumlanmasından daha fazla faydalanabildiği görülmüştür. Bunun da sebebinin yeni başlayan terapistlerin yorumlardan faydalanabilecek düzeyde içgörü kazanamamış olmaları bulunmuştur. Yeni başlayan terapistlerle çalışırken, kaygı düzeyini azaltmak ve temel terapötik becerilerin gelişmesi için somut ve yapılandırılmış müdahalelerin daha etkili olduğu savunulmuştur (McNeill ve Worthen, 1989).

Bir başka araştırma, paralel sürecin varlığını destekleyecek önemli bulgular sunmuştur (Tracey ve diğerleri, 2012). On yedi farklı süpervizör-terapist-danışan grubunu inceleyen çalışmada, paralel süreç kavramına uygun şekilde davranış değişikliklerinin olduğu kaydedilmiştir (Tracey ve diğerleri, 2012). Buna ek olarak, eğer terapist süpervizörün davrandığı gibi davranmaya başlarsa danışanın iyi yönde ilerlediği kaydedilmiştir (Tracey ve diğerleri, 2012). Terapötik ve süpervizyon ikilisinin ortak üyesi olan terapist önce terapi ilişkisinde örüntüyü süpervizyona taşımakta ve sonra süpervizyonda konunun ele alınışını modelleyip terapi ilişkisine taşımaktadır (Tracey ve diğerleri, 2012). Bu sonuçlar paralel sürecin süpervizyon için gerekli ve kullanışlı bir araç olduğunu desteklemekle kalmayıp paralel süreç gibi karmaşık kavramların bile görgül yöntemlerle sınanabileceğini göstermiştir (Watkins, 2012).

\section{Paralel Süreç Mekanizmaları}

Paralel sürecin nasıl ortaya çıktığı konusunda birden fazla mekanizma savunulmuştur (Grey ve Fiscalini, 1987). Farklı kuramsal yönelimlerden paralel sürecin nasıl ortaya çıktığına dair fikirler ortaya atılmıştır ve henüz paralel sürecin nasıl işlediğine dair bir mutabakat sağlanamamıştır (Morissey ve Tribe, 2001). Özdeşim ve yansıtmalı özdeşimin paralel sürecin altında yatan savunma mekanizmaları olabileceği ortaya konulmuştur (Searles, 1955; Grey ve Fiscalini, 1987).

Searles'a göre (1955), bilinçdışı özdeşim paralel sürecin altında yatan savunma mekanizmasıdır. Paralel süreç, danışanın bastırdığı ya da ayrıştırdığı duygularının gün yüzüne çıkması ile başlamakta, bu nedenle danışanda kaygı yükselmekte ve buna karşı savunma mekanizmaları işletilmektedir. Ortaya çıkan kaygı karşısında terapist kişisel özellikleri ile alakalı olarak kendi kaygısını tecrübe etmektedir. Sonrasında, bilinçdışında yükselen bu kaygı deneyimi ile terapist ya danışanın kaygı karşısında kullandığı savunma mekanizmalarının aynısını ya da tamamlayıcı şekilde olan savunma mekanizmalarını kullanmaya başlamaktadır. Bu şekilde terapist bilinçdışı ve sözel olmayan bir şekilde süpervizöre terapide ortaya çıkan sorunun doğası hakkında fikir vermektedir (Searles, 1955). 
Yansıtmalı özdeşim mekanizmasında ise danışan terapistin içine duyguyu yerleştirmekte ve sonrasında da terapist de süpervizörün içine o duyguları aktarmaktadır (Grinberg, 1979). Bu duyguların kaynağı süpervizör ya da terapist değildir, dolayısıyla karşı aktarım kavramı ile açıklanmamaktadır (Grey ve Fiscalini, 1987). Bu noktada, ortaya çıkan durumun bitmemiş karşı aktarım meseleleri ya da çözülmemiş nevrotik çatışmalardan kaynakladığı yönünde itirazlar yükselmektedir; öte yandan, paralel sürecin ortaya çıkmasına sebep olan duygusal deneyimlerden kurtulabilecek kadar yüksek bir farkındalık ve beceri düzeyinin mümkün olmadığı savunulmuştur (Searles, 1955).

Özdeşim ve yansıtmalı özdeşim savunma mekanizmalarıyla paralel süreci açıklamak, paralel sürecin danışanın nevrotik ihtiyaçlarından kaynakladığını ve terapist ile süpervizörün taşınan mesajların alıcısı olduğunu söylemektir (Grey ve Fiscalini, 1987). Önceki açıklamalar birbirleriyle yakından ilişkilidir ama bir yandan da paralel sürecin farklı kısımlarına odaklanmışlardır (Morissey ve Tribe, 2001). Grey ve Fiscalini, önceki açıklamaların dar kapsamlı ve test edilemez olması nedeniyle paralel süreci yeni bir bakış açısı ile ele almışlardır (1987). Bu bakış açısı, paralel süreci birbirine yapısal ve dinamik olarak benzeyen sadece psikoterapi ve süpervizyonda değil tüm kişilerarası durumlarda ortaya çıkabilecek olan bir zincirleme reaksiyon olarak ele almıştır. Güç ve yakınlık boyutları olan tüm ilişki serilerinde ortaya çıkabileceğini savunmuşlardır (Grey ve Fiscalini, 1987). Bunun yanı sıra, paralel süreçteki rollerin karşılıklı olabileceği kadar birbirlerini tamamlayıcı da olabileceği savunulmuştur (Mothersole, 1999). Bu noktada terapist ve süpervizör mesajın alıcı konumundan sıyrılıp süreçte aktif olarak yer aldıkları düşünülmektedir. Grey ve Fiscalini (1987) paralel süreci Berne’nin (1964) “oyun” kavramı ile açıklamışlardır. Oyun kavramı iki ya da daha fazla kişi arasında tekrar eden davranış örüntüleri olarak tanımlanmıştır ve kişilerin aynı oyun içerisinde karşılıklı ve birbirini tamamlayan rollerde bulunabileceği savunulmuştur (Berne, 1964). Örnek olarak, eğer bir kişi “b davranışı” karşısında "a davranışını" gösteriyorsa cevap olarak, sonraki durumda "b davranışını" gösterip cevap olarak “a davranışını” görebilir. Paralel süreç birbirinin içine geçmiş aktarım ve karşı aktarımlardan oluşan, tarafların benzer savunma stillerine çekimiyle bağlanan danışan, terapist ve süpervizör üçlüsünün oynadığı bir oyun olarak değerlendirilmiştir. Diğer açıklamalardan farklı olarak bu bakış açısında paralel süreç katılımcıları danışanın nevrotik ihtiyaçları karşısında durumsal olarak benzeşmez, zaten ilk andan itibaren birbirlerine bazı önemli açılardan benzemektedirler. $\mathrm{Bu}$ sebeple aynı duygusal çatışma karşısında benzer savunma biçimlerini kullandıkları düşünülmektedir.

Paralel sürecin açıklanmasında diğer bir görüş de kişilerarası kuramdan gelmektedir (Tracey ve diğerleri, 2012). Güç ve yakınlık boyutları tüm insan ilişkilerinin içerisinde bulunmaktadır ve neredeyse tüm ilişkiler bu boyutlar açısından incelenebilir (Tracey ve diğerleri, 2012). Bununla beraber, bir kişinin davranış biçimi karşı tarafın onu nasıl yanıtlaması gerektiği bilgisini de taşımaktadır. Her davranış, kişinin kendini ilişkide nasıl konumlandırdığını göstermektedir (Tracey ve diğerleri, 2012). Bu bilgiler 1şığında bir paralel süreç örneği aşağıda açıklandığı gibi oluşmaktadır (süpervizyon ve terapinin basite indirgenmeyecek kadar karmaşık bir yapıda olduğunu kabul etmekle beraber anlatımın kolaylığı için basitleştirme yoluna gidilmiştir): danışan yardım alma amacıyla terapiye başlar (teslimiyetçi davranış) ve terapist de yardım ederek bu davranışı tamamlar (baskın davranış). Sonrasında danışan terapistin müdahalelerini boşa çıkarır (güvensiz davranış) ve terapist de bu durum karşısında eleştirel bir tutum izler ve bu konu süpervizyona taşınır. Süpervizyonda da benzer bir kişiler arası örüntü gerçekleşir (terapistin yardım alma amacıyla süpervizyona başvurması ile başlayan) (Tracey ve diğerleri, 2012). Özetlemek gerekirse, süpervizör-terapist-danışan üçlüsünün birbirini tamamlayıcı 
davranışları sürecin temelini oluşturmaktadır.

\section{Paralel Sürecin Çözülmesi}

Süpervizyonda paralel sürecin işlenmesi gerekli görülmektedir (Sumeral, 1994). Paralel süreç bir araç olarak süpervizyonda etkili bir şekilde kullanıldığında terapistin gelişimine katkıda bulunmaktadır ve dahası paralel süreç süpervizyonda ele alındığında danışanda da gelişme olduğu kaydedilmiştir (Doehrman, 1976).

Searles'a göre (1955) paralel süreç neticesinde ortaya çıkan kaygı en fazla danışanda bulunmaktadır ve önce terapiste sonra da süpervizöre doğru ilerledikçe bu kaygı miktarı azalmaktadır. Bu azalma en yüksek farkındalık düzeyinin süpervizörde olması ve duygusal olarak en az süpervizörün yatırım yapmasından kaynaklanmaktadır. Bu durumdan mütevellit, süpervizör daha rahat bir şekilde bilinçdışı materyali sözel olarak ele alabilmektedir. Süpervizyon ilişkisi ilerledikçe ve farkındalık düzeyi arttıkça süpervizör-terapist ikilisi kendilerini gözlemleyebilir ve terapötik açıdan anlamlı olan bu içgörüden faydalanır hale gelmektedir (Searles, 1955).

Çözülme hakkında bir farklı görüş de kişilerarası kuramdan gelmektedir (Tracey ve diğerleri, 2012). Bu görüşe göre süpervizör ilk etapta terapistin danışandan taşıdığı materyal karşısında tamamlayıcı bir rol edinmekte ve sonrasında süpervizör kasıtlı olarak bu rolde değissim yapmaktadır. Süpervizyonda gelişen bu değişim ardından terapötik sürece de yansımakta ve farklı beklentiler ile alternatif davranışların gündeme gelmesine yardımcı olmaktadır (Tracey ve diğerleri, 2012).

Süpervizyonda paralel sürecin ele alınabilmesi için süpervizörün farkındalık düzeyinin yüksek olması elzemdir (Sumeral, 1994; Morissey ve Tribe, 2001). Paralel süreci etkin bir şekilde kullanmak için tarafların "ilişkide neler oluyor" sorusunun cevabını iyi anlamaları gerekmektedir (Carroll, 1996). Bu tarz bir bilgiyi kullanmanın terapistin, süpervizyon ve terapide nasıl ilişki kurduğu yönünde de aydınlatıcı olduğu düşünülmektedir (Sumeral, 1994). Paralel süreci hedef alan müdahalelerin neticede terapistin gelişimine yardımcı olacağı ve bu şekilde danışanın iyilik haline katkıda bulunacağı öne sürülmüştür (Sumeral, 1994).

Paralel süreç ile çalışırken her durumu paralel süreç olarak yaftalanması veya paralel olarak gelişen süreçlerin tespit edilememesi riski vardır (Feltham ve Dryden, 1994; Mothersole, 1999). Bunun yanı sıra, paralel süreç süpervizyonda kullanılacak etkili bir araçtır fakat tek başına yeterli bir araç değildir (Raichelson ve diğerleri, 1997). Morissey ve Tribe (2001) paralel süreci hedef alan müdahalelerin zamanlamasının da önemli olduğunu vurgulamaktadır. Sonuç olarak, paralel süreç ile çalışırken yapılan müdahalenin yardım edici ve terapötik olduğunu gösteren en büyük gösterge terapi sürecinde fayda sağlanıp sağlanmadığıdır (Sumeral, 1994; Morissey ve Tribe, 2001).

\section{Vaka Çalışması}

\section{Öncül hikaye}

Behzat Bey, özel sektörde hekim olarak çalışan 38 yaşında erkek bir danışandır ve terapiye uçak korkusu şikâyetiyle başvurmuştur. Behzat Bey terapiye başlamadan önce sakinleştirici kullanarak uçağa binmiştir ve terapideki amacı bunu ilaç yardımı olmadan yapabilmektir. Uçağa binme korkusunun, eşi 4 aylığına Hollanda'da çalışma yapmaya gittiğinde, kendisini eşinin yanına gitmekten alıkoyduğunu ifade etmiştir. Bu olaydan sonra Behzat Bey bu sorununu çözmesi gerektiğini düşünmüştür. 
Birkaç seans geçtikten sonra Behzat Bey'in uçak korkusunun altında kontrolcülük ile alakalı meselelerin yattığı ortaya çıkmıştır. Hayatını planlı ve programlı geçiren Behzat Bey, eğer bir şeyler ters giderse her zaman alternatif planlara sahiptir. Behzat Bey'in uçak korkusu, uçuş sırasında beklenmedik bir durum ortaya çıkarsa "bir şey yapamayacak" oluşundan kaynaklı olabileceği düşünülmüştür. Kendisi durumu "eğer arabada bir şey olursa arabayı durdurursun; eğer, gemide bir şey olursa atlar ve yüzersin" diye özetleyip "eğer uçakta bir şey olursa yapabileceğin bir şey yok" şeklinde aktarmıştır.

Behzat Bey için başka bir sorun alanı ise stres altındayken ortaya çıkan somatik yakınmalarıdır. Bu somatik yakınmalar genellikle mide ya da tansiyon ile alakalıdır. Behzat Bey durumu "bazen o kadar saçma belirtiler hissediyorum ki bedenimde, bir doktor olarak bunların gerçek olamayacağını biliyorum” şeklinde ifade etmektedir. Bu yakınmalar yakından incelendiğinde Behzat Bey’in kendisini “arada kalmış” hissettiği durumlarda ortaya çıktığ 1 görülmüştür. İlk yakınmasının ebeveynleri tartışırken arada kaldığında ortaya çıktığını aktarmıştır. Ebeveynleri Behzat Bey’i aralarındaki meseleyi çözmesi için Bursa'ya çağırmışlardır (Behzat Bey Ankara' da yaşamaktadır). Vardığında meseleyi çözmeye çalışmıştır fakat çözemeyeceğini anladığı anda tansiyonunun yükselmeye başladığını hissetmiştir. Bunun üzerine Behzat Bey kalp krizi geçirdiğini düşünüp dehşete kapılmıştır. Behzat Bey hastaneye gittikten sonra ebeveynleri Behzat Bey'e "konuyu kafaya takmamasını, kendilerinin halletmeye çalışacaklarını" söylemiştir. Burada da somatik yakınmalar da Behzat Bey’in kontrolcülüğü ile ilişkilidir. Somatik yakınmalar Behzat Bey’e meseleyi kontrol edip bir plan neticesinde çözemediğinde bir çıkış kapısı sağlamıştır.

Behzat Bey’in annesi bağımsız yaşayamayan pasif bir kadındır. Behzat Bey “Otobüse bile tek başına binemez" şeklinde tanımlamıştır. Öte yandan, babası askeri bir kariyeri olan baskın bir figürdür. Behzat Bey, ebeveynleri arasındaki ilişkinin tatmin edici olmaması nedeniyle psikolojik anlamda annesinin bakımını üstlendiğini belirtmiştir. Annesine defalarca evliliğinde mutlu değilse boşanmayı düşünmesi gerektiğini ve boşanmadan sonra kendisinin ona destek olacağını söylemiştir. Fakat Behzat Bey’in annesi babasından ayrılmamıştır. Behzat Bey babasının kendisine karşı her zaman eleştirel olduğunu söylemiş ve Tıp Fakültesini kazandığında babasının İngilizce eğitim veren bir Tıp Fakültesine girememesi yönünde eleştirdiğini aktarmıştır.

Behzat Bey ile başlayan terapinin odak noktası kontrolcülük olmuştur. Sunulan tablo da aşağıdaki şekilde kavramsallaştırılmıştır: baskın bir baba figürü ve pasif bir anne figürüne sahip Behzat Bey annesini babasının eleştirelliğinden korumak için kendisini öne sürmüştür. Annesi için kendisini feda ederken babasının kendisine vermiş olduğu suçlu konumunu kabullenmiş ve suçluluğu üzerine almıştır. Kontrolcülüğü de bu suçluluktan kaçınmak için kullanmıştır. Eğer her şey kontrol altında olursa hiçbir şey yanlış gidemez ve dolayısıyla suçluluk hissedecek bir durum ortaya çıkmaz şeklinde bir varsayımı olduğu düşünülmüştür. Bu strateji hayatı boyunca iyi işlemiş fakat ölüm gibi kontrol edemeyeceği bir durum ortaya çıkınca Behzat Bey’i yüzüstü bırakmıştır. Annesi ve babası arasındaki sorunlar Behzat Bey'in semptomlarının çıkmasından çok önce var olmasına rağmen, Behzat Bey bedeninin kendisine ihanet edip ölebileceğini fark ettiğinde semptomları ortaya çıkmıştır.

\section{Terapi süreci ve süpervizyon sürecindeki paralellikler}

Önceden bahsedildiği gibi Behzat Bey’in terapisinde kontrol ile alakalı mevzulara odaklanılmıştır. Örneğin, seans içinde gündemden sapmalar yaygın olarak görülmüştür. Behzat Bey seans içerisinde bir konu üzerine konuşmayı kabul etmekte fakat seanslar bahsi geçen konu üzerine derinleşemeden bitmekteydi. Süpervizyon sürecinde de süpervizör ve terapist de bu vaka ele alınırken farklı noktalara odaklanmak istemiştir. Buna örnek olarak, terapist vaka ile kontrolcülügün gündelik hayatına etkisi üzerine gitmek isterken süpervizör terapist-danışan ilişkisi 
üzerinde yoğunlaşmak istemesi gösterilebilirdi. Süpervizyon ve terapi süreci, belli konularda çalışma üzerine karar verilmişken tarafların farklı noktalar üzerinde yoğunlaşmak istemesi açısından birbirine paralel olduğu düşünülmüştür. Terapist anlaşılmamış olduğunu hissetmiş ve süpervizörün anlatmak istediği konuları dinlemek istemediğini varsaymıştır. Bu da terapistin süpervizörünün kendisini eleştirdiğini düşünmesine yol açmıştır. Bu konu süpervizyon sürecinde ele alındığında danışanın terapist tarafından eleştirildiğini ve yanlış anlaşıldığını hissediyor olabileceği yönünde bir farkındalık ortaya çıkmıştır. Bu bilgi ışı̆̆ında, terapistin seanslarda konu dışına sapmaların çok olduğunda konunun dağılmamasına yönelik efor sarf etmesinin durumu daha da kötüleştirdiği yönünde bir yorum ile bu konuyu gündeme taşımıştır. Bunun üzerine Behzat Bey o konular üzerine konuşmanın bile kendisini çok zorladığını ifade etmiş ve konuşmaya devam etme konusunda da kaçışının olmadığını söylemiştir. Bu yüzleştirmeden sonra seans içinde gündem dışına kaymalar giderek azalmış ve kararlaştırılan konular üzerine konuşma noktasında bir birlik ortaya çıkmıştır.

\section{Sonuç}

Vaka örneğinde de gösterildiği gibi, süpervizyon ile terapi süreçleri arasında paralellikle ortaya çıkmıştır. Searles'ın (1955) da ortaya koyduğu gibi danışan kaynaklı bir kaygı terapi sürecine giriş yapmış ve terapist aracılığıyla süpervizyon sürecine taşınmıştır. Süpervizyonda paralel süreci ele almak işe yaramış ve terapi sürecinde de bir ilerleme kaydedilmiştir. Vaka örneğinin Searles tarafından sunulan paralel süreç modeliyle uyumlu olduğu görülmüştür (1955). 


\section{Kaynaklar}

Berne, E. (1964). Games People Play. New York: Grove.

Carroll, M. (1996). Counseling Supervision Theory, Skills and Practice. London: Cassell.

Doehrman, M. J. G. (1976). Parallel Processes in Supervision and Psychotherapy. Bulletin of the Mellinger Clinic, 40, 3-104.

Ekstein, R., ve Wallerstein, R. S. (1958). The Teaching and Learning of Psychotherapy. New York: International Press.

Feltham, C., ve Dryden, W. (1994). Developing Counselor Supervision. London: Sage.

Grey, A., ve Fiscalini, J. (1987). Parallel Process as Transference-Countertransference Interaction. Psychoanalytic Psychology, 4(2), 131-144.

Grinberg, L. (1979). Countertransference and Projective Counteridentification. Contemporary Psychoanalysis, 15, 226-247.

McNeill, B. W., ve Worthen, V. (1989). The Parallel Process in Psychotherapy Supervision. Professional Psychology: Research and Practice, 20(5), 329-333.

Meerloo, J. A. M. (1952). Some Psychological Processes in Supervision of Therapists. American Journal of Psychotherapy, 6, 467-470.

Morissey, J., ve Tribe, R. (2001). Parallel Process in Supervision. Counselling Psychology Quarterly, 14(2), 103-110, doi: 10.1080/09515070110058567

Mothersole, G. (1998). Levels of Attention in Clinical Supervision. Transactional Analysis Journal, 28(4), 285-296.

Mothersole, G. (1999). Parallel Process. The Clinical Supervisor, 18(2), 107-121. doi: 10.1300/J001v18n02_08.

Lesser, R. M. (1983). Supervision: Illusions, Anxieties, and Questions. Comtemporary Psychoanalysis, 18, 1-19.

Raichelson, S. H., Herron, W. G., Primevera, L. H., ve Ramirez, S. M. (1997). Incidence and Effects of Parallel Process in Psychotherapy Supervision. The Clinical Supervisor, 15(2), 37-48, doi: 10.1300/J001v15n02_03

Sachs, D. M., ve Shapiro, S. H. (1976). On Parallel Processes in Therapy and Teaching. Psychoanalytic Quarterly, 45, 394-415.

Searles, H. F. (1955). The Informational Value of Supervisor's Emotional Experiences. Psychiatry, 18, 135-146.

Sumeral, M. B. (1994). Parallel Process in Supervision. Eric Digest, 94(15).

Tracey, T. J. G., Bludworth, J.,ve Glidden-Tracey, C. E. (2012). Are There Parallel Processes in Psychotherapy Supervision? An Emprical Examination. Psychotherapy, 49(3), 330-343.

Watkins, C. E. J. (2012). Some Thoughts about Parallel Process and Psychotherapy Supervision: When is a Parallel just a Parallel? Psychotherapy, 49(3), 344-346. 


\section{Summary \\ Parallel Process in Psychotherapy Supervision: A Case Study}

The concept of "Parallel Process" is widely recognized in psychotherapy supervision literature (Morissey \& Tribe, 2001; Raichelson, Herron, Primevera, \& Ramirez, 1997; Grey \& Fiscalini, 1987). Supervision of psychotherapy is essentially a triadic process where a therapist is supervised in his/her work with one or more clients (Tracey, Bludworth, \& Glidden-Tracey, 2012). The concept refers to unconscious replication of relational patterns both in therapeutic dyad (consisting of therapist and the patient) and supervisory dyad (consisting of supervisor and supervisee/therapist) (McNeill \& Worthen, 1989). Many authors perceived parallel process as an important tool in supervision and a valuable form of communication (McNeill \& Worthen, 1989; Morrissey \& Tribe, 2001). Interventions focused on parallel process may improve the quality of supervisory process (Morrissey \& Tribe, 2001). Parallel process received attention in the field, though, empirical support was relatively deficient (Grey \& Fiscalini, 1987; Raichelson, et al., 1997; Tracey, et al., 2012). Parallel process has its origins in psychoanalytic concepts of transference and countertransference (Sumeral, 1994; McNeill \& Worthen, 1989; Morissey \& Tribe, 2001). However, some authors avoided to render parallel process within the realm of countertransference (e.g. Searles, 1955). On the other hand, existence of parallel process is confirmed without affirming the unconscious aspects (Raichelson, et al., 1997; Tracey, et al., 2012). Parallel process is defined as a unidirectional process in which the process is triggered by the unconscious of the patient (Grey \& Fiscalini, 1987; Searles, 1955). However, some authors refer it as a bidirectional process, where the starting point may be either the patient or the supervisor (Doerhman, 1976; Tracey, et al., 2012). In conjunction with the complex nature of supervision and therapy, parallel process is to be portrayed as a circular dynamic rather than a process with a start point (Morissey \& Tribe, 2001). Some authors claim that it is an interlocking processes of the supervisor, therapist, and patient triad, a "game" that the triad play (Grey \& Fiscalini, 1987).

Mr. T is 38-year-old male patient who works as a physician in private sector. He started therapy for his phobia of planes. However, before he started therapy, he tried to get on plane under the effect of mild tranquilizers. He stated that he would like to manage enplaning without the help of drugs. His fear of planes disabled him to go Netherlands while his wife was on a sabbatical for four months. After that incident, he came to realize this was a problem he has to deal with.

Over the course of a few sessions, it was revealed that his fear about plane was actually related to his overall controlling attitude. Mr. T is a person who lives according to his schedule, and always has alternative plans if anything goes amiss. The fear of planes, in his case, is due to his "not being able to do anything" if something unexpected happens during the flight. He reported "if something goes wrong in a car, you stop; if something happens on a ship, you jump out and swim" and added "when something happens on a plane, there is nothing you can do about it."

The most prominent features in Mr. T's therapy process are clustered around the control related issues. For instance, digressions from the ongoing agenda within sessions were common. Mr. T willingly agrees upon on a topic to explore in sessions; on the other hand, sessions end up without deepening on that particular subject. In supervisory sessions, therapist and supervisor wished to focus on different aspects when this case was handled. For example, the therapist wanted to probe more about the current effects of controlling attitude on patient's work and social life, the supervisor gave directions intensifying on the relationship between the therapist and the patient. The supervisory and therapeutic processes were parallel in a manner that in both dyads no de facto consensus was reached on process' agenda; although, in both relationships it was agreed upon to work on some particular issues. Therapist felt misunderstood, and assumed that supervisor 
did not wanted to listen to what he tried to recount. Hence, the therapist thought the supervisor was critical of him. As this was verbalized in supervisory process, an insight about the fact that the patient might have felt misunderstood and criticized by the therapist, surfaced. In the light of this insight, therapist commented on how in sessions the conversation went off topic and his efforts to stay on topic make the situation worse, Mr. T expressed he felt forced when he actually has difficulties even talking about the subject matter. After that confrontation, digressions within the sessions gradually decreased, and the alliance on exploration of topics boosted.

As illustrated in the case example, parallel situations occurred in both therapeutic dyad and supervisory dyad. As Searles (1955) highlighted, an anxiety originating from patient introduced into the therapeutic relationship (the one directional model), and conveyed through therapist to supervisor. Working on parallel process issues on supervisory dyad paid well, and a progress have been made in the therapeutic relationship. The case illustration fitted well to parallel process model of Searles (1955). 